\title{
CONCEPÇÃO E SIGNIFICADO DE “UM SÉCULO DE ENSINO PRIMÁRIO”
}

\author{
A. B. N. T. MENEZES \\ Universidade Federal do Rio Grande do Norte \\ antoniobasilio62@gmail.com
}

Artigo submetido em 19/08/2019 e aceito em 19/08/2019

DOI: $10.15628 /$ holos.2019.8905

\section{RESUMO}

O objetivo deste texto é a análise da obra "Um Século de Ensino Primário" (1927a) de Nestor dos Santos Lima tomada no contexto das comemorações do centenário da primeira lei que regulamenta o ensino primário no Brasil em 1827 apresenta três níveis de estruturação discursiva no quadro de referências da produção intelectual do autor na década de 1920, especificamente no ano de 1927. O autor apresenta o significado de "Um Século de Ensino Primário" não apenas como um livro comemorativo do centenário, mas antes como o sentido preservado da lei de 1827 no cuidado da criação e provimento das escolas e nos princípios fundamentais da organização administrativa, do método de ensino, do regime disciplinar e da formação dos professores como um modelo ideal de educação e um projeto nacional.

PALAVRAS-CHAVE: Ensino primário, História da Educação, Historiografia.

\section{CONCEPTION AND MEANING OF "A CENTURY OF PRIMARY EDUCATION"}

\section{ABSTRACT}

The aim of this text is the analysis of the work "A Century of Primary Education" (1927a) by Nestor dos Santos Lima taken in the context of the celebrations of the centenary of the first law that regulates the primary education in Brazil in 1827 presents three levels of discursive structuring in the of the author's intellectual production in the 1920s, specifically in the year 1927. The author presents the meaning of "A
Century of Primary Education" not only as a commemorative book of the centenary, but rather as the preserved sense of the law of 1827 in the care of the creation and provision of schools and in the fundamental principles of administrative organization, method of teaching, disciplinary regime and teacher training as an ideal model of education and a national project.

KEY WORDS: Primary education, History of Education, Historiography.

\section{CONCEPCIÓN Y SIGNIFICADO DE "UN SIGLO DE ENSEÑANZA PRIMARIA"}

\section{RESUMEN}

El objetivo de este texto es el análisis de la obra "Un Siglo de Enseñanza Primaria" (1927a) de Nestor de los Santos Lima tomada en el contexto de las conmemoraciones del centenario de la primera ley que regula la enseñanza primaria en Brasil en 1827 presenta tres niveles de estructuración discursiva en el " el cuadro de referencias de la producción intelectual del autor en la década de 1920, específicamente en el año 1927. El autor presenta el significado de "Un Siglo de Enseñanza Primaria" no sólo como un libro conmemorativo del centenario, sino más bien como el sentido preservado de la ley de 1827 en el cuidado de la creación y provisión de las escuelas y en los principios fundamentales de la organización administrativa, del método de enseñanza, del régimen disciplinario y de la formación de los profesores como un modelo ideal de educación y un proyecto nacional.

PALABRAS CLAVE: Enseñanza primaria, Historia de la Educación, Historiografía. 


\section{CONSIDERAÇÕES INICIAIS}

Para as letras; para a arte, Com tino extraordinário,

Erigiu, por toda parte, Aulas de ensino primário. Lei prudente, lei preclara, De um cunho tão senhoril, Em preceitos bons traçara, Novos rumos ao Brasil. (Nestor Lima - Hino do 10 centenário do ensino primário)

A obra "Um Século de Ensino Primário" (1927a) de Nestor dos Santos Lima tomada no contexto das comemorações do centenário da primeira lei que regulamenta o ensino primário no Brasil em 1827 apresenta três níveis de estruturação discursiva no quadro de referências da produção intelectual do autor na década de 1920, especificamente no ano de 1927. Com uma perspectiva hegeliana da "coruja de Minerva" que alça vôo ao entardecer (HEGEL, 1997) o texto comemorativo reúne outras camadas discursivas além da descrição da trajetória do ensino no Brasil e no Rio Grande do Norte nesses cem anos que separam a publicação da lei da obra.

Inserida no quadro histórico-educacional dos anos 20 a obra traduz na sua especificidade as demandas de construção de um discurso a nível nacional e local que caracterizam o quadro histórico da educação brasileira na época. E não se reduz apenas a condição local do desenvolvimento da educação em cem anos, mas agrega um projeto político nacional vigente, naquele momento, de unificação do ensino, as vésperas do I Conferencia de Educação realizada em Curitiba em 1927.

Reunião de artigos semanais e diários do então Diretor do Departamento de Educação do Estado, publicados no jornal "A República", "órgão oficial dos Poderes do Estado" a coletânea "Um Século de Ensino Primário" (LIMA, 1927a) faz espelhamento ao conjunto da produção intelectual do autor na década de 1920 em que se dedica ao tema da educação. Destacando no ano de 1927 a publicação do artigo "As razões do Centenário" (LIMA, 1927b) pela Revista Pedagogium, órgão da Associação de Professores no número comemorativo do Centenário; as teses apresentadas na I Conferência de Educação: "Unificação do Magistério Nacional" (LIMA, 1927c) e "O Celibato Pedagógico Feminino" (LIMA, 1927d); bem como o discurso do encerramento oficial das comemorações do Centenário de 15 de outubro de 1927 (LIMA, 1927e) publicado num opúsculo sobre as festas centenárias pela Associação de Professores.

Publicação oficial comemorativa do ano do centenário "Um Século de Ensino Primário" (LIMA, 1927a) traz no seu conteúdo uma revisão da evolução histórica do ensino 
primário no Brasil do Império até a República nos anos de 1920. E examina sob o marco da lei de 1827 a evolução do ensino nos dois períodos, passando do contexto nacional para o local, pautando-se na documentação oficial disponível em atas, falas governamentais, relatórios e leis.

A história monumentalizada nos documentos (LE GOFF, 2003) descreve "a obra colossal de organização nacional, iniciada corajosamente naquela memorável década, no aspecto educativo" (LIMA, 1927a, p. 3) sob a ótica retroativa da coruja hegeliana que estrutura o discurso oficial de uma história consumada vista a partir do fim como "a base segura em que repousaria o melhor futuro da nossa pátria" (LIMA, 1927a, p. 3). Característica narrativa de uma história construída a partir de documentos oficiais, a composição do livro corresponde à conformação de um discurso em torno de uma concepção geral de educação articulada em torno do ensino primário que passa a ser o telos último e organiza a partir do presente todo o sentido histórico do processo. Sendo este último configurado para além do conteúdo histórico descritivo como uma matriz de pensamento, presente no entrecruzamento dos diferentes aspectos: do exercício do magistério, da política educacional e do projeto nacional que envolvem a discussão da evolução do ensino primário no Brasil e no Rio Grande do Norte.

Assim, as diferentes camadas que constituem o significado da obra "Um Século de Ensino Primário" (LIMA, 1927a) corresponde uma análise do discurso que extrapola os elementos internos inerentes a sua conformação e o situa no quadro das referências externas das relações extradiscursivas que Ihe imprimem sentido. E as camadas discursivas Ihe conferem um tríplice enquadramento: (a) no conjunto da produção intelectual do autor como diretor da Escola Normal de Natal e Diretor do Departamento de Educação do Estado nas décadas de 1910 e 1920; (b) no contexto local das discussões sobre as condições do exercício do magistério e a política educacional do Rio Grande do Norte do discurso oficial acerca das suas realizações; e (c) na projeção do Rio Grande do Norte no concerto de um projeto nacional de modernização da educação no Brasil.

\section{QUADRO REFERENCIAL: ESTRUTURA E COMPOSIÇÃO DA OBRA}

Opúsculo dedicado ao Presidente do Estado1 com "admiração e reconhecimento" (LIMA, 1927a, p. 2) publicado pela imprensa oficial do Estado em comemoração ao centenário da lei de 15 de outubro de 1827 que regulamenta o ensino primário no Brasil, a coletânea de artigos de Nestor Lima no diário "A República" que compõe a obra "Um Século de Ensino Primário" se estrutura em torno do significado e importância da lei. Esta última, considerada como uma "grande e notável promessa ou fundamento que se faz sentir por todos os recantos do território brasileiro" (LIMA, 1927a, p. 3) se faz abstraída do seu

\footnotetext{
${ }^{1}$ Nomenclatura do período republicano até 1930 para designar o Governador do Estado.
} 
contexto histórico, como paradigma de uma concepção de educação expressão das demandas política e de ensino do Rio Grande do Norte.

A organização temporal da obra em dois blocos - Império e República - dá-se concomitante a composição da obra enquanto uma reunião de artigos como corpo do texto e os anexos reunindo diferentes documentos voltados para as ações e realizações do governo no ano de 1927. A elisão do contexto histórico isola-a da sua condição temporal de uma lei do Império no momento da afirmação do regime republicano como a ruptura do antigo pelo moderno. Obliterada a condição histórica da lei sob a camada descritiva dos textos da coletânea, o autor organiza uma glosa de informações sob a forma de "notícias" (LIMA, 1927a) a partir dos documentos do período.

A organização temporal também corresponde um deslocamento espacial no eixo da narrativa que passa do contexto nacional para o local, marcando a inserção da história do ensino primário no Rio Grande do Norte a partir do capítulo sobre "os resultados imediatos da lei centenária" o qual faz menção aos excelentes frutos da lei que cria as aulas de primeiras letras por todo país. O que, ainda na década de 1820, coube ao Conselho de Província potiguar criar "dezoito escolas de primeiras letras, sendo dezesseis para meninos e duas para meninas equitativamente distribuídas" nas regiões populosas da "nascente" Província (LIMA, 1927a, p. 46).

De modo definitivo o deslocamento espacial da perspectiva histórica do ensino primário, do âmbito nacional para o âmbito potiguar se dá no capítulo sobre "as conseqüências indiretas da lei de 1827" ao considerar apenas aquelas que refletem as condições do ensino primário no Rio Grande do Norte. Isto é, nas palavras do autor, "a progressão das escolas e suas freqüências nos decênios consecutivos até 1889", em torno dos quais se destaca "a demonstração do empenho que aquela lei despertou na consciência dos dirigentes da Nação e da Província em relação ao problema momentoso da educação popular" (LIMA, 1927a, p. 51).

A organização de "Um Século de Ensino Primário" (LIMA, 1927a) traduz no conjunto da coletânea um significado articulado na disposição dos textos em duas partes distintas: aquela que diz respeito à lei, seu conteúdo e repercussão; e aquela que diz respeito ao quadro de evolução temporal do ensino no Império e na República. Sendo que no eixo da sua articulação encontra-se uma concepção de ensino que tem na lei seu núcleo estruturador sinalizado na análise da evolução histórica.

O exame da lei de 1827 traduz no seu conteúdo o eixo dos diferentes aspectos que compõem uma concepção central de ensino estabelecida em torno: (a) do exercício do magistério; tipo de ensino e condições relativas a prática docente; (b) da política educacional; papel e contexto de desenvolvimento do ensino; e (c) da identidade nacional; integração e inserção do ensino potiguar num projeto nação. Contudo a concepção de ensino de "Um Século de Ensino Primário" (LIMA, 1927a) também se apresenta no quadro de referências de outros textos da produção intelectual de Nestor Lima no ano de 1927 que sinalizam estes aspectos. 
$O$ artigo no número comemorativo da revista Pedagogium, órgão oficial da Associação dos Professores, com o título "As razões deste Centenário" (LIMA, 1927b) traz uma síntese da concepção de ensino de Nestor Lima sob o tríplice aspecto: do exercício do magistério; da política educacional; e da identidade nacional que articulam o núcleo discursivo de "Um Século de Ensino Primário" (LIMA, 1927a). Evocando "os aplausos entusiásticos e uníssonos que a idéia deste Centenário despertou no espírito dos que se interessam pela sorte da educação" (LIMA, 1927b, p. 3) o autor destaca nas razões do centenário o marco histórico da lei na sistematização da instrução primária com a criação das "cadeiras de primeiras letras"; a uniformização do ensino, sua "organização didática e regime disciplinar"; e "a maneira de investidura do professorado, regulando-lhes os direitos, vantagens e obrigações" (LIMA,1927b, p. 5). Todos esses elementos enfatizados sob o sentido histórico de um ideal de ensino que se afirma em torno de uma proposta de "instrução primária nacional por todos os recantos do território brasileiro" (LIMA, 1927b, p. $6)$.

Tal concepção de ensino também se encontra presente no discurso de encerramento das "festas oficiais comemorativas do Centenário do Ensino Primário" (LIMA, 1927e), proferido pelo autor no Theatro Carlos Gomes em 15 de outubro de 1927. Acercando-se do desafio da educação como tema central seu discurso articula aspectos políticos e educacionais da lei como motivo de jubilo nacional "que possuíra o mérito de colocar sob a égide protetora da nação, a causa sacrossanta da instrução do povo que é o primeiro e essencial fundamento da sua educação" (LIMA, 1927e, p. 55-56).

Apoiado no desdobramento político da lei, Nestor Lima associa ao desafio nacional da educação a importância da participação de diferentes segmentos da sociedade Imprensa, Igreja e Governo - envolvidos na realização das comemorações que tinham como "única preocupação: a de chamar para o magno e vital problema nacional a atenção e as energias dos homens de boa vontade [...] visando realizar os seus mais belos propósitos com a educação generalizada do povo brasileiro" (LIMA, 1927e, p. 56). Rendendo ao final do seu pronunciamento o "tributo cordial do grande reconhecimento e da maior admiração dos que se desvelam pela sorte da infância e da juventude norte-rio-grandense, [...] na humildade das oficinas de civismo - as escolas primárias" (LIMA, 1927e, p. 57).

De modo mais prático a concepção de ensino de Nestor Lima também se consubstancia nas teses apresentadas no ano de 1927, na I Conferência de Educação defendendo as propostas de unificação do magistério e do celibato feminino. As teses centradas nas condições do sistema de ensino e na formação do magistério revelam as matrizes de estruturação da sua concepção que se assenta sobre esses dois pilares e a projeta no contexto nacional.

De um lado, a tese "Unificação do Magistério Nacional" (LIMA, 1927c) ressalta a dimensão política nacional de integração dos Estados sob a ótica da unidade do ensino no sistema federado através do "reconhecimento da validade dos diplomas expedidos pelas Escolas Normais dos Estados brasileiros, dentro do território de outros Estados" (LIMA, 1927c, p. 5). Estabelecendo o autor a equivalência do ensino e o nivelamento da formação dos professores como premissa de uma política nacional, na medida em que "a 
multiplicidade das organizações estaduais deve-se sobrepor o interesse geral e unitário da pátria e da verdadeira educação nacional" (LIMA, 1927c, p. 6).

De outro lado, a tese "O Celibato Pedagógico Feminino" (LIMA, 1927d) ao tratar "da condição da mulher casada em face da educação e do ensino como profissão habitual" defende o celibato como condição para o magistério, apoiado no exemplo de Minas Gerais cuja reforma primária "só dá acesso ao magistério a professoras solteiras ou viuvassem filhos" (LIMA, 1927d, p. 3). A tese centrada nas premissas da eficiência técnica e do perfil profissional elenca os mais diferentes argumentos de ordem eugenista e econômica frente aquilo que se espelha no Rio Grande do Norte como "francamente desfavorável ao ensino público, sempre as voltas com as ausências da suas regentes em virtude das licenças especiais" (LIMA, 1927d, p. 5, grifo do autor).

Assim, o enquadramento dos referenciais estabelecidos no curso da produção intelectual de Nestor Lima deixa entrever nos textos do ano do centenário o eixo político pedagógico que serve de balizamento ao exame histórico de "Um Século de Ensino Primário" (LIMA, 1927a). E se traduz numa concepção de ensino que aparece na base da construção do seu significado.

\section{A OBRA E O SEU SIGNIFICADO}

Em "Um Século de Ensino Primário" a história argumenta uma concepção de educação que reuni no caráter fragmentário da coletânea o significado da lei de 1827 como eixo de abordagem dos diferentes textos. Divididos temporalmente nos períodos do Império e da República, na organização da obra os textos referentes ao primeiro período tratam apenas da lei, enquanto aqueles do outro descrevem um quadro de evolução histórica tendo o significado da lei por parâmetro.

A obra também compreende na sua divisão os "Anexos" que complementam a evolução do quadro histórico com os dados atuais e evidenciam a dimensão política do seu conteúdo. Os cinco anexos apresentam as iniciativas governamentais através de atos, documentos oficiais e entrevistas que desenham a evolução do ensino no Rio Grande do Norte no ano do centenário. Do mesmo modo que tomados em conjunto constituem um texto paralelo cujo significado se encontra disperso, implícito no próprio conteúdo dos documentos.

Os "Anexos" complementam a parte dedicada ao conteúdo e as consequências da lei, e permitem estabelecer um núcleo de argumentação em torno do significado que revela uma concepção de modernização do ensino no seu lastro histórico e no âmbito local das iniciativas no Rio Grande do Norte. Articulados ao corpo da obra eles revelam o estofo do ideário republicano do ensino como força motriz da ordem e do progresso na interpretação dado conteúdo da lei de 1827. 
Entrelaçando os aspectos do tipo de ensino, condições do magistério e iniciativas educacionais, a interpretação da importância do centenário apresenta na composição da obra os elementos de uma concepção de ensino primário que reflete no quadro temporal da década de 1920 a evolução de um projeto local com extensão nacional. A universalização e a modernização do ensino primário potiguar enquanto móvel do desenvolvimento do país descreve então como estofo de toda argumentação em torno do texto da lei, das suas providencias, do método de ensino, do regime disciplinar, do provimento das escolas e "recompensas do magistério" (LIMA, 1927a, p. 35), como ainda os resultados imediatos da lei e as consequências indiretas.

Ao tratar do significado da comemoração do centenário a introdução que nomeia a obra "Um Século de Ensino Primário" abre o livro situando a data sob o marco histórico da atualidade que:

há cem anos antes já existia uma noção mais ou menos segura do valor da profissão ensinante, que merecia a consagração legal e especiais prerrogativas que hoje um século após, ainda não existem em alguns departamentos da União Brasileira, não obstante avanços que se tem realizado nesse particular (LIMA, 1927a, p. 4).

Na mesma medida em que o texto inicial também destaca a importância da comemoração não ser apenas "mais um centenário dentre os muitos já relembrados", mas ao contrário, "incontestavelmente um dos mais de perto ligados a base da verdadeira organização social e cultural da nossa nacionalidade" (LIMA, 1927a, p. 6). Ao que se segue na ordem dos textos a transcrição da integra da lei sob a proposta de "fazer uma exposição metódica do assunto" (LIMA, 1927a, p. 7).

Para Nestor Lima as providencias "salutares" da lei de 1827 elencam-se:

A instituição do ensino primário oficial e a criação de "escolas elementares" nas cidades e vilas mais populosas, dada realidade "de que houvesse uma única escola régia na antiga capitania do Rio Grande durante o período colonial" (LIMA, 1927a, p. 12);

O interesse "pela maior das obrigações do Estado moderno" com a organização das "escolas régias" sob a "perspectiva que "a instituição popular seguisse as normas praticadas nas escolas dos outros países avançados" (LIMA, 1927a, p. 12-13);

A adoção do "plano de ensino com as matérias a serem ministradas", concomitante a "metodização das lições e a organização das classes", bem como a utilização do sistema disciplinar de Lancaster e do "modo mútuo" de Bell (LIMA, 1927a, p. 12).

O autor estabelece a relevância da lei de 1827 cem anos depois, a partir das providencias dos artigos 60 e 12ㅇ ou da adoção do "plano sistemático do ensino elementar" com a descrição dos seus conteúdos, bem como "aquelas mesmas disciplinas fundamentais" que decorridos cem anos equiparam-se ao plano de ensino dos Grupos Escolares enquanto "escolas primárias mais adiantadas". Do mesmo modo que faz corresponder as "atuais 
escolas rudimentares ou escolas de simples alfabetização" (LIMA, 1927a, p. 13) as necessidades, os anseios e mesmo os fins da cultura as exigências que se encontravam na lei.

Acerca da implantação do "modo mutuo" de ensino de André Bell ${ }^{2}$ pela lei de 1827 , Nestor Lima salienta a característica técnica de este ser "a base de todo ensino" ou ainda "o modo que mais se usa e tem sido usado desde os primórdios da instrução", enfatizando a exigência do artigo 50 que remonta a difusão e padronização do "modo de organização e regência das escolas" bem como a necessidade de uma formação específica para o magistério em função de tal "inovação" (LIMA, 1927a, p. 17; p. 20). Sendo que, no que se refere ao regime disciplinar, o autor assinala no artigo 150 a recomendação do uso do método lancasteriano, como um "sistema de penas recompensas a ser observado pelos mestres aos seus alunos" em oposição à disciplina do castigo físico aplicada. Denotando a sua proximidade com as concepções mais modernas, embora "poucos professores tiveram tempo de aprendê-lo sequer de praticá-lo" dado o Ato Adicional de 12 de agosto de 1834 que "passou para as antigas Províncias o direito de legislar sobre a instrução primária" (LIMA, 1927a, p. 27-28).

É ainda em torno dos efeitos do Ato Adicional de 12 de agosto de 1834 que o autor traça sua crítica ao período imperial nos marcos administrativo da criação e provimento das escolas, da implementação do método de ensino e do regime disciplinar, considerados sob a perspectiva histórica do "bosquejo das teorias adotadas na lei" (LIMA, 1927a, p. 29) nas bases da construção de uma proposta geral de instrução pública e concepção do ensino primário que se queria efetivar.

A lei de 1827 assinala a interdependência dos poderes no artigo $2 \circ$ o qual:

competia ao Presidente de Província criar escolas de primeiras letras, mas em sessão do Conselho de Província e depois de ouvidos a Câmara de cada município, dando de tudo conta à Assembléia Geral na Corte para resolução final (LIMA, 1927a, p. 29).

O que demonstraria para o autor uma harmonia e compatibilidade da organização administrativa na criação das escolas de primeiras letras, consolidada cem anos depois na ideia de que "a criação das escolas depende de cada um desses poderes: o Município, o Estado e a União" (LIMA, 1927a, p. 30).

Do mesmo modo, quanto ao aspecto do provimento das escolas, Nestor Lima assinala a "idéia vitoriosa" da lei que estabelece o sistema de provimento por concurso público "que perdurou até os nossos dias" (LIMA, 1927a, p. 32-33), sendo ele um avanço na exigência de formação específica para o magistério, o qual "põe a mostra, em provas públicas ou em títulos de merecimento a aptidão especial dos que tendem a ensinar" (LIMA,

\footnotetext{
${ }^{2}$ Segundo Lima (1927a, p. 18, grifo do autor): "André Bell (1753 - 1832), afamado pedagogo inglês adotou em Madras na India [...] o modo de ensino que ele denominou mutuo ou monitorial, e no qual o professor ensinava as lições aos mais adiantados, monitores ou decuriões (por analogia a organização do povo e do exército romano) e estes por sua vez tomavam ou ensinavam as lições a dez (decúria) alunos mais atrasados ou médios".
} 
1927a, p.31). Embora o autor se manifeste contrário a este modo de provimento declarando:

Não nos enfileiramos, porém entre os adeptos do velho sistema de concurso que a lei de 15 de outubro adotou para provimento dos cursos iniciais. Preferimos em toda linha, o sistema das Escolas Normais, hoje existentes em todos os países do universo. (LIMA, 1927a, p. 33).

Assim, dentro do quadro temporal do significado da lei de 1827 como sendo os primeiros passos da construção de concepção geral de instrução pública e do ensino primário, Nestor Lima desdobra as críticas e iniciativas que corroboram ou impedem a realização deste ideal, sob a ótica da descontinuidade entre os períodos da Monarquia e da República.

\section{O MARCO TEMPORAL DA DESCONTINUIDADE E O FIM DE UM CICLO}

Para Nestor Lima a descontinuidade temporal entre Monarquia e República na evolução de um século de ensino primário, coloca-se superposta a ideia de um ciclo de realização do ideal da instrução pública preconizado na lei de 1827. Colocando sob exame a organização da instrução, criação de escolas, adoção de regime disciplinar, uniformização do ensino e formação do magistério, seus parâmetros de análise indicam um ciclo de tentativas e dificuldades que se estendem até o equacionamento do problema do ensino primário com o decreto de 29 de abril de 1908.

A situação geral da instrução no período monárquico descreve a estagnação do ensino primário frente ao impulso inovador da lei de 1827, como atestam as falas dos presidentes da Província do Rio Grande entre 1835 e 1860, a exemplo do pronunciamento de Manoel Ribeiro da Silva, o "Parrudo", que na abertura da sessão legislativa em 7 de setembro de 1837 "si nada adianta sobre o número de escolas, propugna entretanto pela reforma que atinja o duplo fim do ensino, isto é, 'instruir o entendimento e formar o coração'" (LIMA, 1927a, p. 60). Corroborando neste mesmo período as falas presidenciais de 1845 e 1849: de Casemiro de Moraes Sarmento sobre o estado deplorável da instrução, lembrando a "decretação do ensino obrigatório" (LIMA, 1927a, p. 63); e de Boaventura de Magalhães Taques sobre a carência de preparação dos professores e o atraso na instrução primária.

Refletindo sobre as deficiências administrativas da monarquia no período entre 1850 e 1870, Nestor Lima ilustra o atraso da instrução na Província do Rio Grande e a precariedade de se implementar ações efetivas com relação aquilo que "a propósito da lei de 15 de outubro 1827 ocupa lugar de acentuado relevo" (LIMA, 1927a, p.75). Isto é, a indissociabilidade entre a criação e provimento das escolas, a situação do ensino e do magistério que, nas palavras do autor, as falas presidenciais "feriam continuamente a nota 
dos males que embaraçavam o serviço e apontavam meios de curá-los" (LIMA, 1927a, p. 81) embora frente a este ideal apresentassem carência de efetividade na prática.

Correlato ao diagnóstico do "triste painel do atraso do ensino público" e as causas atribuídas "à ignorância, indiferença, pobreza dos pais e a falta de habilitação e zelo por parte dos mestres", o autor ressalta contrapartida algumas iniciativas como "idéias assentes hoje em nossas leis" (LIMA, 1927a, p. 83-84), tais como aquelas presentes nas propostas do relatório do presidente da Província em 1862:

um curso para individuo candidatos ao magistério; conversão de uma das aulas da capital em escola prática modelo [...] divisão das cadeiras em três entrâncias; proibição ao professor de exercer outros misteres; organização de uma boa inspeção escolar e a fundação de uma sociedade de pais de famílias para uma caixa escolar" (LIMA, 1927a, p. 83).

Nestor Lima apresenta na evolução da instrução primária os sinais do seu esgotamento evidente nas últimas décadas do império como um campo de disputa delineado em torno do cenário de discussão da época sobre o ensino de primeiras letras. Nas suas próprias palavras: "uns proclamando-lhe as virtudes; outros thes prodigando os defeitos, suas causas e consequencias nefastas" (LIMA, 1927a, p. 95). Assim, ao balanço geral da instrução pública no período antecedente a República, entre 1877 e 1889, se segue as críticas de Nestor Lima a situação do ensino primário e o número e provimento das escolas, ao que pese fatores atenuantes da "ação terrível da grande seca" cuja época "sombria e trágica" exauriu o erário público "e só as rendas gerais é que podiam fazer face aos gastos da seca" (LIMA, 1927a, p. 103).

As esperanças de que com a República viria a solução do problema da educação "magno assunto que tão intima e visceralmente interessa a coletividade nacional nos seus fundamentos essenciais" - dá lugar à frustração da proposta que "a União viria assumir os encargos da educação popular" (LIMA, 1927a, p. 133). Nestor Lima censura a Constituição de 24 de fevereiro de 1891 ao deixar aos municípios os encargos com a instrução primária, em prosseguimento a "situação precária desse serviço" com "péssimos resultados, por muitos anos, em várias unidades federativas brasileiras" (LIMA, 1927a, p. 134). Oportunidade em que também critica a lei estadual número 131 de 13 de setembro de 1899 que "tornando municipais as cadeiras de instrução primária, criadas ou vacantes, abriu para o ensino público uma nova era de desprestigio e calamidade" (LIMA, 1927a, p. 149).

Imbuído do ideário republicano e da crença nas intenções dos governos de melhoria da instrução pública, Nestor Lima traça sua crítica nos limites do discurso oficial, não raro da "reação necessária" da unidade federativa que "não cuida desvelada e eficazmente do seu ensino primário, nele empregando todos os recursos que pode dispor" (LIMA, 1927a, p. 134). Assim, frente aos percalços históricos que perduraram na manutenção precária do ensino, o autor elenca nas falas oficiais e nos relatórios da primeira década republicana algumas iniciativas como: o decreto de criação da Escola Normal em 1890; a reorganização da instrução pública em 1892 que previa entre outras medidas "a intervenção fiscalizadora 
dos municípios [...] sob as ordens da Diretoria Geral da Instrução Pública" (LIMA, 1927a, p. 137); e a instalação do curso Normal em 1897.

Para Nestor Lima "a situação do ensino primário no Estado, entregue aos municípios, era a mais desalentadora e deplorável", a qual "urgia uma reação que quanto mais enérgica e radical, tanto mais proveitosa e benéfica resultaria" (LIMA, 1927a, p. 165). Assim, a autorização da lei número 249 de 22 de novembro de 1907 de "reformar a instrução pública dando especialmente ao ensino primário moldes mais amplos e garantidores de sua proficuidade" vem em resposta aos clamores de reorganização do ensino em novas bases, encerrando - nas palavras do autor - "o período histórico iniciado com a famosa lei de 15 de outubro de 1827 e desdobrado pelos sucessivos regulamentos cuja vigência prolongara a influencia da referida lei" (LIMA, 1927a, p. 160).

A proposta de uma reforma radical, efetivada por decreto em abril de 1908 marca no fim de um ciclo histórico a descontinuidade entre as bases de um projeto de educação esboçado pela lei de 1827 no início do Império, com a criação de escolas e a organização do ensino; e um novo horizonte que se abria no período republicano com um novo ciclo de realizações do ensino potiguar. A criação do Grupo Escolar Augusto Severo pelo decreto número 174 de 5 de março de 1908 dá início ao processo de reorganização da instrução pública ao qual sucede o decreto de 29 de abril de 1908 com "a reforma integral da instrução primária e secundária, e a criação do curso profissional pedagógico nos termos da autorização ampla da lei número 249 de 22 de novembro de 1907" (LIMA, 1927a, p.167).

A reforma da instrução soerguida pelos pilares da criação de escolas, da organização do ensino e da formação do magistério consolida em torno do Grupo Escolar e da Escola Normal um novo modelo de ensino. A medida extrema de supressão de "todas as cadeiras existentes deixando em disponibilidade todos os respectivos professores" se seguem a implantação de Grupos Escolares "em cada sede de comarca e uma escola mista nos demais municípios" (LIMA, 1927a, p. 167). Do mesmo modo que a formação do "pessoal técnico das escolas primarias estaduais passou a ser preparado cuidadosamente na Escola Normal" reinaugurada em 13 de maio de 1908 (LIMA, 1927a, p. 167; p. 171).

A preocupação com a rede escolar e a formação do magistério, com a criação dos Grupos Escolares e a implementação do Curso Normal se associam ao remodelamento do ensino não apenas na forma de organização, mas também no que diz respeito ao método e a disciplina escolar. A capacitação do pessoal técnico bem como a nova organização administrativa proporcionada pela reforma de 1908 traduz as exigências de ensino, centrado no novo modelo do Grupo Escolar ${ }^{3}$ que, como proposta de modernização da instrução pública, se afirma não apenas no Rio Grande do Norte, mas em toda nação neste período. Com isto, aquilo que Nestor Lima assevera como fim do "período histórico iniciado com a famosa lei" (LIMA, 1927a, p. 160) traduz, mais do que o corte temporal, a implantação de um novo modelo na solução do problema da instrução pública que se coloca como um projeto nacional.

\footnotetext{
${ }^{3}$ A esse respeito informa Lima (1927a, p. 172) "o decreto 198 de 10 de maio de 1909 declarou que o Grupo Escolar Augusto Severo, desta capital serviria de modelo para prática dos normalistas e para experimentação de métodos e processos aplicáveis ao ensino primário".
} 
A exigência de organização do ensino de que "o novo estabelecimento teria três cadeiras, sendo uma masculina, outra feminina e a mista, sob a regência de professores contratados ou diplomados" (LIMA, 1927a, p. 166-167), corresponde à definição das disciplinas a serem ministradas e ao método a ser adotado: "lições concretas, variadas, concisas e acessíveis a inteligência dos meninos e por processos intuitivos" (LIMA, 1927a, p. 167), bem como a abolição dos castigos corporais e a instituição do "sistema de prêmios e penas morais tão em voga em outros centros educativos" (LIMA, 1927a, p. 167, grifo do autor). Sendo que este modelo de ensino se reproduzirá nas décadas subsequentes, norteando as iniciativas dos sucessivos governos na expansão da rede escolar e nas iniciativas de aperfeiçoamento da legislação nos períodos de 1910 e de 1920, tal como apresenta o autor ao listar as mudanças na regulação jurídica e os números discriminados da criação de escolas em cada governo.

Por fim, o Grupo Escolar preconiza uma formação integral que vincula a organização do ensino, o regime disciplinar e a formação dos professores, no cerne uma proposta de modernização que guarda apenas o espírito da lei centenária nos seus princípios orientadores e no seu fim. Assim, Nestor Lima traça um quadro evolutivo, encerrando de modo aporético a trajetória de "Um Século de Ensino Primário" na descrição das leis e iniciativas que do presente ao futuro se coloca na prospecção do novo, sobre o qual o próprio sentencia: "Está concluída a nossa tarefa porque sobre os méritos dessas reformas só poderão dizer com isenção os que não a tem praticado desde o início" (LIMA, 1927a, p. 173).

\section{CONCLUSÃO}

A obra como um legado histórico deixado ao registro das realizações e iniciativas perpetradas por regimes e governos em um século de ensino, caracteriza além da elaboração de um discurso oficial em torno da melhoria da instrução, outro fator político: a legitimação da implantação de um modelo para educação e o ensino, não fosse 1927 o último ano de Nestor Lima a frente do Departamento de Educação do Estado, empreendedor da reorganização administrativo educacional no período de 1924 a 1928. Desse modo, toda a narrativa histórica do livro é atravessada por uma concepção de ensino que reverbera as conquistas da instrução potiguar em bases nacionais, da importância da educação e da proposta de modernização do ensino como fator de unidade nacional, formação do povo e implementação do progresso.

Ao cabo Nestor Lima apresenta o significado de "Um Século de Ensino Primário" não apenas como um livro comemorativo do centenário, mas antes como o sentido preservado da lei de 1827 no cuidado da criação e provimento das escolas e nos princípios fundamentais 
da organização administrativa, do método de ensino, do regime disciplinar e da formação dos professores como um modelo ideal de educação e um projeto nacional.

\section{REFERÊNCIAS}

HEGEL, G. W. F. (1997). Princípios da filosofia do direito. Tradução de Orlando Vitorino. São Paulo: Martins Fontes.

LE GOFF, J. (2003). História e Memória. Tradução de Bernardo Leitão et. al. Campinas: Unicamp.

LIMA, N.S. (1927a). Um Século de Ensino Primário. Natal: Typographia d" "A República".

LIMA, N.S. (1927b). As razões deste centenário. In: ASSOCIAÇÂO DE PROFESSORES. As Festas Centenárias do Ensino Primário. Discursos. Pedagogium, número comemorativo, p. 3-6.

LIMA, N. S. (1927c). Unificação do Magistério Nacional. Natal: Typographia Commercial - J. Pinto \& L.

LIMA, N.S. (1927d). O Celibato Pedagógico Feminino. Natal: Typographia Commercial - J. Pinto \& L.

LIMA, N. S. (1927e). Discurso do Dr. Nestor Lima, pronunciado a 15 de outubro de 1927, no Teatro Carlos Gomes encerrando as festas oficiais comemorativas do Centenário do Ensino Primário. In: ASSOCIAÇÂO DE PROFESSORES. As Festas Centenárias do Ensino Primário. Discursos. Pedagogium, número comemorativo, Natal, p. 55-57.

LIMA, N.S., SMIDO, L. M. (1927f). Hino do Primeiro Centenário do Ensino Primário no Brasil: para quatro vozes brancas comacompanhamento de piano. Rio de Janeiro: Casa Bevilacqua. 